\title{
Autos fiscales con Don Pedro de Córdova, vecino de La Plata (Charcas), sobre el derecho a una encomienda que tenía su mujer, Doña Teresa de Avendaño, en los indios de Atacama, cuyo pueblo permutó por otro, a causa de haber querido el Virrey, Marqués de Cañete, fundar allí una población para poderse comunicar con Chile. (Año 1562) \\ Biblioteca Nacional de Buenos Aires (BNBA) \\ Colección de copias de documentos del Archivo General de Indias. Colección G. García Viñas. Documento 1400.
}

Transcripción de GaSPar García Viñas

Suplica se le de çedula para que los offiçiales le dexen gozar de los yndios charcas que son 160 y les restituyan los fructos y se cunplan las çédulas del virrey.

muy poderoso señor.

Alonso de herra en nonbre de don pedro de cordoua vezino de la ciudad de los Reyes por virtud del poder que del tengo del qual hago presentación digo que al tienpo quel dicho mi parte caso con doña teresa de avendaño su muger se le encomendaron mili y quinientos yndios que la dicha su muger tenia en encomienda que se dizen los yndios de atacama que son en los confines de chile y tiniendo los dichos yndios en encomienda y estando en pacifica posesión dellos el marques de cañete vuestro visorrey que fue entendiendo que convenia a vuestro rreal seruiçio hazer vna población en el dicho sitio de atacama para mejor comunicarse con la población y gente de chile y de tucuman questa en el paso y para que los que fuesen y bieniesen hallasen acogida y mantenimientoz trato con el dicho don pedro mi parte de permutar los dichos yndios con otros en esta manera que el dicho don pedro dexase los dichos yndios de atacama y se pusiesen en la corona rreal para el dicho efeto y que el dicho birrey le encomendaría los yndios charcas que son hasta ciento y sesenta yndios y asi se hizo efetuo el dicho contrato y el dicho virrei encomendó los dichos yndios de atacama a Juan velasques altamirano para el dicho efeto que alli hiziese población y rresidiese y encomendó en el dicho mi parte los dichos yndios charcas y estando mi parte en pacifica posesión dellos después desto el conde de nieva vuestro visorrei que al presente es en la rrevocacion general que hizo de las encomiendas que habia hecho el marques de cañete y rrevoco la dicha encomienda de charcas que a mi parte estaua hecha y le desposeio de los dichos yndios y los puso en vuestra corona rreal después de lo qual mi parte se agrauio antel dicho virrei y alego de su justicia y entendido que la tenia tan notoria y que el dicho marques de cañete no le avia hecho merced sino contratado y permutado con el muy en vuestro rreal seruiçio y en pro y vtilidad de vuestra rreal hazienda mando bolver y rrestituyr al dicho mi parte los dichos yndios charcas y que vuestros oficiales le acudiesen con los tributos corridos y dello dio su çedula y sobre çedula y los dichos vuestros offiçiales no la quisieron cunplir so color de cierta çedula y provision diz que dada por vuestra alteza por la qual mandaua se quitasen al dicho mi parte los yndios y encomienda que abian sido de don alonso de montemayor porque se habia hecho rrelaçion a vuestra alteza que todos los yndios y encomienda que abian sido del dicho don alonso de montemayor se abian dado y encomendado al dicho mi parte no siendo ansi porque solamente se le dieron en la dicha permutación y trueco los dichos ciento y sesenta yndios charcas y el dicho birrei marques de cañete con toda la demás encomienda del dicho don alonso de montemaior por virtud de vna vuestra rreal çedula señalo e situó cinco mili pesos de Renta a don Juan de velasco hijo del mariscal alvarado y lo que mas rrenta la dicha encomienda que fue del dicho don alonso de montemaior se cobra para vuestra alteza por vuestros oficiales rreales como todo lo suso dicho consta por estos testimonios y escripturas que presento y pues el dicho mi parte tiene tan justo titulo a los dichos yndios charcas y la dicha prouision de que se quieren valer los dichos oficiales para no dexar a mi parte vsar de los dichos yndios es de ningun efeto por ser 
ganada subrreticia y obrreticiamente como consta de lo suso dicho porque a mi parte no se le encomendó toda $\mathrm{j}$ la encomienda como a vuestra alteza se hizo rrelacion y aquello que se le encomendó no fue 4 por via de merced sino de contratación como esta dicho por tanto pido e suplico a vuestra \alteza mande dar su rreal prouision mandando se guarden y cunplan la dicha çedula y sobre çedula de vuestro visorrey y en cunplimiento dellas vuestros oficiales rreales dexen gozar libremente a mi parte de los dichos yndios charcas y que le buelvan y rrestituyan los tributos y rrentas corridos y los que corrieren hasta la rreal rrestitucion conforme a lo probeydo por el dicho vuestro visorrey conde de nieba y pido sobre todo cunplimiento de justicia y protesto las costas y en lo necesario vuestro rreal ofiçio ynploro.

El Liçençiado Tobar.- alonso herrera.- [Rubricados] traslado al fiscal de madrid 7 de dizienbre 1563 notificoseme lo suso dicho el dicho dia y año.

[Hay una rúbrica]

[En el dorso se lee: Al Relator.-] [Rubricado]

informaçion ante vn alcalde de los reyes para probar el hecho deste negocio catado el fiscal.

[al margen: probanza echa por don pedro de cordoba con citación del fiscal]

En la ciudad de los Reyes prouinçias del peru a seys dias del mes de septienbre de mili e quinientos y sesenta e vn años antel muy magnifico señor liçençiado aluaro de torres alcalde hordinario en esta dicha ciudad por su magestad y en presencia de mi Juan garçia de nogal escriuano publico parescio don pedro de cordoua vecino desta çibdad e presento dos escriptos con preguntas del tenor siguiente.

muy poderoso señor pedro de cordoua digo que a mi derecho conviene hazer ante vuestra merced cierta ynformacion ad perpetuam rrey memoria $y$ como mejor derecho aya lugar de lo conthenido en las preguntas siguientes.

pido a vuestra merced la mande rrescibir citado el fiscal rreal por lo que toca a la rreal hazienda y lo que los testigos depusieren se me de en publica forma duplicado ynterpuniendo en todo su auturidad y decreto judicial sobre que pido justicia e para ello \&.
Primeramente sean preguntados los testigos si conoscen al dicho don pedro de cordoua y si tienen noticia de los yndios de atacama que fueron encomendados en françisco y pedro de ysasaga por mitad y asimismo de la parte de yndios charcas que fueron encomendados en don alonso de montemayor difunto en los términos de la çibdad de la plata que son los mismos que el marques de cañete visorrey que fue destos rreynos encomendó al dicho don pedro por dexaçion que hizo de los dichos yndios de atacama en que doña teresa de avendaño su muger subçedio.

\section{II}

y ten si saben que el liçençiado gasea presidente destos rreynos encomendó al dicho don alonso de montemayor el rrepartimiento de yndios de xacaca que es vn prençipal rrepartimiento y juntamente con el los dichos yndios charcas como paresce por la çedula de encomienda que della le hizo que se presenta en esta causa.

\section{III}

- yten si saben \& que el dicho marques de cañete visorrey en cunplimiento y execucion de vna Çedula rreal de su Magestad señalo a don juán de velasco hijo menor del mariscal alonso de aluarado cinco mili pesos de rrenta en cada vn año de que su Magestad le hizo merced en los tributos en que estauan tasados los yndios del dicho rrepartimiento de xacaca y que lo que mas valen lo cobran los oficiales rreales de potosy para su Magestad.

\section{IIII}

- yten si saben que en la visita que se hizo por gomez de solis y françisco de tapia y los demás yndios charcas que el dicho don alonso de montemayor tenia no se hallaron por ella mas de ciento y quarenta y un yndios avnqe el caçique y prençipales declararon que abría trecientos y veynte y dos yndios y que los dichos visitadores afirman que no los abra por lo que vieron y entendieron en su tierra como paresce por la visita que dellos hizieron que se presentara en estacavsa.

V

- yten si saben \& que el dicho marques de cañete encomendó al dicho don pedro de cordoua los 
dichos yndios charcas que fueron del dicho don alonso de montemayor porque hiziese dexaçion de los yndios que tenia e poseya en la dicha prouinçia de atacama que ovo con la dicha su muger la quall avia muchos años que los tenia e poseya por suscesion los quales dichos yndios de atacama el dicho marques encomendó ajuan velazquez altamirano para que rresidiese en la dicha prouinçia por estar en despoblado para seguridad de los que por alli pasan a las provincias de chile y tucuman para que sean proveydos de mantenimiento nescesario sin hazer perjuizio ni daño a los naturales.

\section{VI}

- yten si saben que los dichos yndios de atacama de que el dicho don pedro de cordoua hizo dexaçion son mas de mili y quinientos yndios y avnque no an sydo visitados ni tasados por estar en despoblado valen mucho mas y valdrán cada dia que los dichos yndios charcas.

\section{VII}

- yten si saben que todo lo suso dicho es publico y notorio don pedro de cordoua.

muy magnifico señor por estas preguntas demás de las presentadas por parte de don pedro de cordova se hesaminen los testigos que por su parte se presentaron para la provanca que haze ad perpetuam Ren memorian.

[al margen: añadido]

\section{VIII}

- yten si saben que los yndios charcas que el marques de cañete dio al dicho don pedro de cordova por los de atacama no heran ni son la tercia parte de los yndios que tenia e poseya don alonso de montemayor digan lo que saben.

IX

- y, si saben que el dicho marques de cañete ningunos otros yndios dio al dicho don pedro de cordova sino son los dichos yndios charcas ni le hizo otra ninguna merced en el tiempo que fue visorrey destos Reynos sino fue los dichos yndios en rreconpensa de los de atacama.
10

- yten si saben que todo lo suso dicho es publica boz y fama don pedro de cordoua.

y ansy presentado el dicho señor alcalde dixo que mandaua e mando al dicho don pedro de cordoua de ynformacion en rrazon de lo contenido en las dichas preguntas y los testigos que presentaren se examinen al tenor dellas citando primero para ello al fiscal de su Magestad y que porque esta ocupado en otros negocios tocantes al seruigio de su Magestad y execucion de la rreal justicia cometía e cometió la rrecepgion y juramento de los dichos testigos a mi el dicho escriuano e me dio poder conplido para los examinar e lo firmo de su nonbre testigos alonso de valencia y pedro de valverde escriuanos públicos.

E después de lo suso dicho en este dicho dia mes e año dicho ante el dicho señor alcalde el dicho pedro de cordova presento vn escripto del thenor siguiente.

[al margen: pide conpulsoria para sacar escripturas]

muy magnifico señor don pedro de cordoua en la provanca que tengo pedida que se haga sobre los yndios de xacaca y charcas digo que a mi derecho conbiene presentar en esta causa la çedula de encomienda que de los dichos yndios yndios [sic] dio el presidente gasea a don alonso de montemayor y la bisita que se hizo de los dichos yndios charcas y asimismo la çedula de encomienda que el marques de cañete dio a Juan velazquez altamirano de los yndios de atacama y la çedula de encomienda que a mi dio el marques de cañete de los dichos yndios charcas y asimismo el señalamiento que el marques de cañete hizo a donjuán de velazco hijo del mariscal alonso de aluarado de cinco mili pesos en cumplimiento de vna çedula rreal en los tributos de los yndios de xacaca que esta todo en poder del secretario pedro de avendaño.

pido a vuestra merced que citándose primero al fiscal para ello me mande dar y de vn mandamiento conpulsorio para sacar las dichas escripturas sobre que pido justicia e para ello \& don pedro de cordoua.

E presentado el señor alcalde mando se le de al dicho don pedro de cordoua el conpulsorio que pide para 
el efeto en su pedimiento declarado y pitando para ello el fiscal de su magestad e se dio en forma.

\section{[al margen: çitaçion al fiscal]}

E después de lo suso dicho este dicho dia mes e año dichos yo el dicho juan garçia de nogal escriuano publico suso dicho notifique al liçençiado monson fiscal de su magestad en la rreal avdiengia desta çibdad los avctos de suso conthenidos proveydos por el dicho señor alcalde y lo çite para lo en ello contenido siendo testigos françisco lopez secretario de la dicha Real avdiençia juan garçia de nogal escriuano publico.

[al margen: presentación de testigos, liçençiado polo, thesorero antonio bazquez rramirez. diego pantoxa. pedro de luxan.]

E después de lo suso dicho en seys dias del dicho mes de setienbre del dicho año el dicho don pedro de cordoua presento por testigo en la dicha rrazon al lic.enc.iado polo onde gardo y en nueve dias del dicho mes de septienbre del dicho año el dicho don pedro de cordoua presento mas por testigo en la dicha rrazon a antonio rramirez bazquez y en diez dias del dicho mes de septienbre del dicho año presento mas por testigo a diego pantoxa vecino de la villa de la plata y en diez y seis del dicho mes de setienbre presento mas por testigo a pedro de luxan estante en esta dicha çibdad de los quales dichos testigos y de cada vno dellos fue tomado y rregebido juramento en forma de derecho por dios e por santa maria e por las palabras de los santos evangelios e por la señal de la cruz que cada vno dellos hizo con los dedos de sus manos so virtud del qual prometieron de decir verdad en este caso en que son presentados por testigos que fueron presentes françisco de la vega e diego de padilla.

\section{La información.}

\section{[al margen: liçençiado polo]}

$1^{\mathrm{o}}$ testigo. - El dicho liçençiado polo onde gardo vezino de la çibdad de la plata y estante en esta çibdad de los rreyes testigo presentado en forma de derecho e siendo preguntado por el ynterrogatorio dixo lo siguiente.

\section{I}

- A la primera pregunta dixo que conosce al dicho don pedro de cordoua de quatro años a esta parte e tiene noticia de los dichos yndios charcas de mas de doze años y de los yndios de atacama no los a visto pero tiene noticia dellos por aver governado la prouinçia de los charcas y caer el asyento dellos en la dicha gouernaçion.

[al margen: generales]

fue preguntado por las preguntas generales dixo que es de hedad de mas de quarenta años e que no le tocan ninguna de las preguntas generales.

\section{II}

- A la segunda pregunta dixo que la sabe como en ella se contiene porque este testigo vio las $\mathrm{C}^{\mathrm{e}<} \mathrm{i}^{\mathrm{u}} \mathrm{l}^{\mathrm{as}}$ de encomienda e por mandado del dicho presidente gasea este testigo señalo al dicho don alonso los dichos yndios charcas e dividió cierta provincia entre el y el general hinojosa e pablo de meneses en la provincias de las charcas e por esto lo sabe.

\section{III}

- A la terçera pregunta dixo que sabe este testigo la pregunta es publico e notorio que el dicho donjuán de belasco cobra los dichos cinco mili pesos del dicho rrepartimiento de xacaca y que los demás cobran los oficiales rreales en nombre de su magestad y esto lo a oydo decir al thessorero antonio rramirez bazquez e a doña ana de belasco madre del dicho don juan e ese tiene por tan publico e notorio que no se sabe ni a oydo otra cosa en contrario.

IIII

- A la quarta pregunta dixo que este testigo hizo tres partes la provincia de los yndios de chaqui de que hera caçique principal chincha y los dividió en tres partes por novecientos e seys yndios que parescieron por la visita antigua e que tanbien entonzes dixeron los yndios que serán tantos e que este testigo no sabe los que hallaron los dichos françisco de ysasaga y gomez de solis que se rremite a la besita pero que este testigo al tienpo que hizo la dicha debision la dibidio por pueblos e no se contaron los yndios porque asi se concertaron las partes y esto sabe desta pregunta.

V

- A la quinta pregunta dixo que lo contenido en esta pregunta es publico e notorio pero que este testigo no a biesto las çedulas de encomienda mas 
de saber que el dicho altamirano posee los yndios de atacama conthenidos en esta pregunta los quales heran de la dicha doña theresa y subçedio en ellos por fin e muerte de pedro de ysasa su marido e que el dicho don pedro tanbien a oydo dezir este testigo que posee los dichos yndios charcas que fueron del dicho don alonso montemayor los quales se le encomendaron por aver fecho la dicha dexaçion de los yndios de atacama y que este testigo tiene por cosa provechosa y nescesaria para el paso de chile que el dicho camino e paso este poblado como esta y que esta se dize que fue la ocasión de averse encomendado los yndios en el dicho altamirano los dichos yndios de atacama.

\section{VI}

- A la sesta pregunta dixo que los dichos yndios de atacama estos yndios no los a visto ni save lo que rrentan ni lo que pueden rrentar pero que a oydo dezir este testigo que son muchos yndios e que tienen muy buenas minas en su tierra e bailes e costa y esto es publico y notorio y que estando pobladas al paresçer deste testigo según lo que dizen mucho mas darán que los yndios charcas porque los yndios charcas son muy pocos e questo rresponde a esta pregunta.

\section{VII}

- A la setima pregunta dixo que dize lo que dicho tiene lo qual es la verdad e publico e notorio para el juramento que fecho tiene y en ello se afirma y rratifica e firmolo de su nombre el liçençiado polo ante mi joan garfia de nogales escriuano publico.

\section{[al margen: antonio rramirez bazquez]}

$2^{\circ}$ testigo. - El dicho antonio rramirez bazquez testigo presentado por el dicho don pedro de cordova del qual fue tomado y Resçibido juramento en forma de derecho so cargo del qual prometió de dezir verdad e siendo preguntado por el ynterrogatorio dixo lo syguiente.

\section{I}

- A la primera pregunta dixo que conosge al dicho don pedro de cordova e tiene noticia de los yndios de atacama porque los a oydo dezir muchas vezes e que de la parte de los yndios charcas que fueron encomendados en don alonso de montemayor porque conosçe algunos de los caziques y prinçipales del dicho Repartimiento porque a cobrado los tributos dellos por su magestad.

fue preguntado por las preguntas generales dixo que es de hedad de quarenta e cinco años e que no le toca ninguna de las preguntas generales e que dios ayude al que tubiere justicia.

\section{II}

- A la segunda pregunta dixo que se rremite este testigo a la encomienda e posesión que dellos tomo e queste testigo conosçio a vn criado mayordomo de don alonso de montemayor e que dezia que hera su criado y cobraua los tributos por el dicho don alonso de montemayor.

\section{III}

- A la terçera pregunta dixo que sabe la pregunta como en ella se contiene porque este testigo como thesorero de su magestad de la provincia de los charcas e asyento de potosy tiene en su poder la çedula del dicho marques de cañete birrey destos Reynos ynserta en ella la gedula de su magestad e porque como tal oficial de su magestad a cobrado lo rrestante de los cinco mili pesos del dicho rrepartimiento de sacaca e por esto sabe la pregunta.

\section{IIII}

- A la quarta pregunta dixo que se rremite a la vesita e que por ella paresçera.

\section{V}

- A la quinta pregunta dixo que sabe este testigo que el dicho marques de cañete encomendó los yndios charcas al dicho don pedro de cordoua porque le a uisto licuar a un criado suyo los tributos y este testigo como uno de los oficiales dexado de cobrar los dichos tributos por esta causa e lo demás que la pregunta dize lo a oydo dezir publicamente.

\section{VI}

- A la sesta pregunta dixo que a oydo dezir que son muchos yndios los conthenidos en la pregunta y que se tiene muy gran notiçia dellos y que si estuviesen sosegados e paçificos serian provechosos.

preguntado por las preguntas añadidas dixo que sabe la pregunta como en ella se contiene porque como 
oficial de su magestad a cobrado los tributos de los dichos yndios charcas y de sacaca y que apenas son la tergia parte de todo el rrepartimiento los yndios que se dieron al dicho don pedro de cordova.

\section{IX}

- preguntado por la novena pregunta añadida dixo que no sabe este testigo que el dicho marques de cañete aya dado al dicho don pedro de cordua ningunos otros yndios ni rrepartimiento ni pensyon ni pensión [sic] ni tal a oydo decjr este testigo y le paresçe y tiene por aberiguado que si el dicho marques le obiera dado otra alguna Renta al dicho don pedro de cordoua lo oyera decir obiera e supiera e no pudiera ser menos y que esto es la verdad y lo que sabe deste caso so cargo del dicho juramento en que e afirmo e Ratifico e firmolo de su i nombre antonio Ramirez bazquez ante mi joan garçia de nogal, escriuano publico.

diego pantoxa.- 3 testigo.- El dicho diego pantoja vezino de la çibdad de la plata testigo presentado por parte del dicho don pedro de cordoua el qual aviendojurado en forma derecho e siendo preguntado por el ynterrogatorio dixo lo siguiente.

- A la primera pregunta dixo que conosce al dicho don pedro de cordoua e tiene noticia del Repartimiento de yndios de atacama porque a estado en el e sabe que estauan encomendados en los conthenidos en la pregunta porque estuvo en el veniendo de chile e ansimismo sabe que los yndios charcas fueron encomendados en don alonso montemayor demás de sacaca que fue el principal Repartimiento del dicho don alonso montemayor e questa parte de yndios charcas sabe este testigo que se encomendó en el dicho don pedro e que hizo dexagion de la parte que tenia en la dicha provincia de atacama y lo sabe por notoriedad e publica boz y fama y porque vn françisco de guzman como mayordomo del dicho don pedro cobra los tributos de los dichos yndios e asiste en la vecindad por el.

generales. - fue preguntado por las generales dixo que sera de hedad de ginquenta años poco mas o menos e que no le toca ninguna de las preguntas generales.

II

- a la segunda pregunta dixo que sabe que el dicho presidente gasea encomendó en el dicho don alonso de montemayor el Repartimiento de yndios que se dize sacaca e que es muy principal Repartimiento e juntamente con el dicho Repartimiento le encomendó el dicho presidente gasea los yndios charcas que la pregunta dize y lo sabe porque vio este testtigo la çedula de encomienda que al dicho don alonso se le dio de los vnos yndios e de los otros.

III

- A la tercera pregunta dixo que lo contenido en la pregunta es muy publico e notorio e que asy lo a oydo este testigo dezir a los oficiales Reales al qual paresce e se rremite.

IIII

- A la quarta pregunta dixo que no sabe los yndios que los bisitadores hallaron mas que sabe que los en esta pregunta contenidos fueron besitadores del dicho Repartimiento e que se Remite a la dicha besita e a la declaración que en ella hizieron.

V

- A la quinta pregunta dixo que sabe que el dicho con pedro o persona por el thiene los yndios charcas que le fueron encomendados por el dicho marques y que la parte o mitad de los yndios de atacama que el dicho don pedro antes tenia es publico e notorio estar encomendados en el dicho juan belazquez altamirano y que los dichos yndios de atacama fueron muchos años antes deste de doña tereza de avendaño muger del dicho don pedro e esto es publico e notorio en toda la çibdad de la plata donde este testigo es veçino y el dicho don pedro también.

\section{VI}

- A la sesta pregunta dixo que el dicho Repartimiento de atacama tiene este declarante por cosa muy principal e los tiene por muchos yndios e de muchas tierras e que cree y tiene por çierto que son mas de mili yndios e por estar lexos de la çibdad de la plata an estado mucho tienpo de guerra e que agora sabe e tiene por çierto que están de paz mediante lo qual tiene por cierto este declarante que yran en avmento e questo Responde e sabe desta pregunta.

\section{VIII}

- preguntado por las añedidas dixo lo siguiente. A la otava pregunta dixo que este testigo cree y tiene 
por çierto que los dichos yndios charcas que son que se encomendaron al dicho don pedro de cordoua no heran ni son la terçera parte de los yndios encomendados en el dicho don alonzo de montemayor porque son los dichos yndios charcas pocos y sacaca que es el prinçipal rrepartimiento es cabezera e como la muy prinçipal en aquella provincia y estos dichos yndios charcas se dieron al dicho don alonso como por demasya.

[al margen: ojo]

IX

- A la novena pregunta dixo que no sabe este testigo que el dicho marques le diese otros yndios que hiziesen al caso sino los dichos yndios charcas porque vnos moyomoyos que heran del Repartimiento de françisco de tapia e segura son muy poquitos e de poca ynportançia e gente que no puede dar mas tributos que hazer vna chácara en sus tierras o en tierras calientes conforme a su naturaleza los quales dichos yndios moyomoyos serán como treynta o quarenta a su parescer deste testigo.

que esta es la verdad y lo que deste caso sabe para el juramento que fecho tiene e firmolo de su nombre diego pantoja ante mi joan garçia de nogal escriuano publico

[al margen: pedro de luxan]

4. - testigo. - El dicho pedro de luxan testigo presentado por el dicho don pedro de cordoua el qual aviendo jurado en forma de derecho e siendo preguntado por el dicho ynterrogatorio dixo lo siguiente.

\section{I}

- A la primera pregunta dixo que conosce al dicho don pedro de cordoua e tiene noticia de los yndios de la provincia de atacama e sabe que fueron encomendados en françisco de ysasaga e pedro de ysasaga e se los encomendó el presidente gasea de por mitad e tiene notiçia de los yndios charcas que fueron encomendados e don alonso montemayor que el marques de cañete encomendo en el dicho don pedro de cordoua.

fue preguntado por las preguntas generales dixo que es de hedad de mas de quarenta años e que no le toca ninguna de las preguntas generales.
II

- A la segunda pregunta dixo que sabe lo contenido en esta pregunta porque este testigo vido tener e poseer al dicho alonso de montemayor el rrepartimiento de yndios contenido en la pregunta.

\section{III}

- A la tercera pregunta dixo que lo contenido en esta pregunta es publico en este rreyno como paresçera y constara por los titules dello a que se refiere.

\section{IIII}

- A la quarta pregunta dixo que lo que desta pregunta sabe es que este testigo a visto cierta visita que se hizo del rrepartimiento e yndios contenido en esta pregunta e que a lo que se acuerda por ella paresçia aver hasta trezientos e tantos yndios poco mas.

V

- A la quinta pregunta dixo que este testigo sabe porque a visto el titulo dello que el dicho marques encomendó en el dicho don pedro de cordoua los dichos yndios charcas contenidos en la la [sic] pregunta antes desta con que hiziese dexaçion de la parte que thenia de atacama que es la mitad e que sabe que esta parte de atacama la thenia e poseya por subcesion de pedro de ysasaga en quien estauan encomendados como marido de doña teresa de avendaño que subçedio en ellos como su muger e que sabe que el dicho don pedro hizo la dicha dexaçion porque este testigo la a bisto que paso ante antonio de quebedo escriuano e sabe este testigo que el marques de cañete dio y encomendó por la dicha dexaçion los dichos yndios de joan belazques altamirano el qual fue a rrescidir en ellos con comisión del marques por ser justicia mayor de aquella provincia e anparar los yndios della e que esto sabe porque bido al tienpo que el dicho joan belazques se partio desta çibdad los titulos della.

- A la sesta pregunta dixo que según la noticia que este testigo tiene de muchas personas que an estado e andado por aquellas provincias de atacama tiene entendido que toda la provinçia son mas de tres mili yndios y Ricos e que estando bisitados y tasados y conpeliendoles a dar tributos podrían dar mas cantidad que monta lo que dan los yndios que 
el dicho marques dio al dicho don pedro de cordoua e questo sabe desta pregunta.

[al margen: ojo]

\section{VIII}

- A la otaua pregunta añadida dixo que sabe que los dichos yndios que el dicho marques de cañete dio al dicho don pedro no son aun la tercia parte de todo el Repartimiento que el dicho don alonso de montemayor tuvo e poseyó ni Rentan estos dichos yndios el tercio de lo que tenia de rrenta por la tasa el dicho don alonso de montemayor y lo sabe porque este testigo a visto muchas vezes las tasas e avn los yndios pagar los tributos e sabe que lo que Rentan estos charcas por la tasa es hasta tres mili y quinientos pesos escasos y lo que rrentan los demás del dicho rrepartimiento que se dize sacaca que los tenia el dicho don alonso son mas de ocho mili pesos e que por esto lo sabe.

A la novena pregunta dixo que este testigo no sabe ni a oydo dezir que el dicho marques diese otros yndios al dicho don pedro sino son los contenidos en las preguntas antes desta e que si el dicho marques se los vbiera dado no pudiera ser sino que este testigo lo supiera y entendiera y fuera publico en este rreyno e que esto es la verdad y lo que sabe deste caso para el juramento que fecho tiene e firmolo de su nombre pedro de luxan ante mi joan garçia de nogal escriuano publico.

E tomada la dicha ynformaçion el dicho señor alcalde a pedimiento del dicho don pedro de cordoua le mando dar vn testimonio dos o mas della signados $\mathrm{y}$ firmados en manera que hagan fee en los quales y en cada vno dellos dixo que ynterponia e ynterpuso su auturidad e decreto judiçial para que valga e faga fee en juizio e fuera del do quier que paresçiere e de lo suso dicho en como paso yo el dicho escriuano publico di el presente testimonio que es fecha en la dicha çibdad de los rreyes en los dichos dias mes e año dichos y el dicho señor alcalde lo firmo de su nombre testigos los dichos françisco de la vega e diego de padilla e alonso de manuel estantes en esta dicha çibdad.

\section{El liçençiado torres.- [rubricado]}

en fee de lo qual lo fize escreuir en estas diez hojas de a pliego entero con esta en que ua mi signo y en fee dello lo fize aqui.
En testimonio de verdad.

[Hay un signo]

Joan garçia de nogal escriuano publico. [rubricado]

derechos a tres tomines por hoja, tres pesos y lo demas se quita.

[Hay una rúbrica]

Nos los escriuanos de su magestad e publicos del numero desta çibdad de los Reyes provinçias del peru que aqui firmamos nuestros nombres damos fee que el liçençiado torres cuya firma es la desta otra parte contenida es alcalde hordinario en esta dicha çibdad y se cunplen sus mandos y mandamyentos como de tal juez y juan garçia de nogal cuyo signo e firma es el desta otra parte contenido es escriuano publico del numero desta çibdad y a los autos y escripturas que antel an pasado e pasan se a dado e da entera fee e credito en juizio y fuera del como de tal escriuano de lo qual dimos esta fee que es fecha en los rreyes veinte de setienbre de mili y quinientos y sesenta y vn años.

alonso de balençia escriuano publico. juan de padilla [rubricados]

[al margen: encomienda de los indios de atacama por dexaçion de don pedro a juan velazquez]

V

- Encomienda en juan velazquez altamirano.

[al margen: encomienda de los yndios atacamas en juan velasquez altamirano son atacamas]

don hurtado de mendoça marques de cañete guarda mayor de la çibdad de cuenca viso Rey e capitan general en estos Reynos e provincias del peru por su Magestad \& porquanto juan velazquez altamirano me hizo Relaçion quel a ocho años poco mas o menos tienpo questa en estos dichos Reygnos donde a seruiçio a su magestad en lo que se a ofreçido y particularmente que al tienpo que don Sebastian de castilla y egas de guzman se alçaron en la çibdad de la plata y asiento de posoty provincia de los charcas contra el servicio de su Magestad alonso de ariaca cavdillo de egas de guzman fue con quinze hombres arcabuzeros al asyento de porco y le prendio a el 
y a otras personas y los truxo al dicho asiento de potosy donde el dicho egas de guzman le quito sus armas y le puso pena de muerte que no saliese del dicho asyento e que desde a çiertos dias antonio de luxan le llamo y entraron en el aposento donde estaban presos martin de almendras e gomez de solis y juan vendrell y prendieron al dicho egas de guzman y soltaron a los dichos presos y ayudo hasta que se hizo justicia del y de otros aliados suyos y se Reduxo el esquadron que tenia hecho al seruiçio de su magestad e que al tienpo que el mariscal don alonso de alvarado fue al dicho asyento a entender en el castigo y allanamiento de lo suso dicho estubo en su acompañamiento y por su mandado fue a la provincia de los chiriguanaes y truxo preso a juan de santa cruz y otros delinquentes y aviendose entendido en la dicha provincia de las charcas el alcamiento de françisco hernandez giron veçino de la çibdad del cuzco y otros hizieron en ella contra el seruiçio de su magestad vino en su acompañamiento del dicho mariscal y del estandarte Real que traya con sus armas e cavallo y truxo a su costa diez soldados con sus armas desde el dicho asyento de potosy a la çibdad del cuzco y de allí hasta el valle de chuquinga donde se hallo en el Recuentro y batalla que se dio al dicho françisco hernandez girón e fueron desbaratados y salió Robado de todo quanto avia llevado que valia cantidad de pesos de oro y acudió al canpo de su magestad que llebaban los oydores desta Real abdiençia contra françisco hernandez $\mathrm{y}$ topo a gomez de solis que y va proveydo por capitan de las çibdades de ariquipa arriba y se fue con el y llegado a la çibdad de ariquipa le nonbro por capitan de su magestad y dio a su cargo toda la gente que avia en ella donde se torno adereçar de armas y cavallos y se hallo al tienpo que juan de piedrahita maestre de campo del dicho françisco hernandez entro en la dicha çibdad y los desbarato y le Robaron lo que tenia y que por mandado del liçençiado altamirano oydor en esta Real abdiençia que Resyde en esta çibdad de los Reyes y justicia mayor de la dicha prouinçia de los charcas fue al baile de tarija donde estaba juan nuñez de prado con sesenta hombres y entre ellos algunos delinquentes y los desbarato e truxo preso a juan de santa cruz de quien se hizo justicia y que por mi horden fue a la prouinçia de atacama con veynte hombres y truxo de paz a la obidencia de su magestad los naturales della y abio a don garcia de mendoça governador de las provincias de chile y la gente que llebaba donde paso trabajos e hizo muchas costas en todo lo qual a servido a su costa como bueno y leal vasallo de su magestad syn aver deservido en cosa alguna y que hasta gora no se le a hecho gratificación dello e me pidió e suplico que atento lo suso dicho le hiziese la merced que fuese seruiçio con que se sustentase y por mi visto por la presente en nonbre de su magesade e por virtud de su Real poder que para ello tengo su tenor del qual es este que se sigue Don carlos por la diuina clemencia enperador senper augusto Rey de alemania doña juana su madre y el mismo don carlos por la misma gracia de dios Reyes de castilla de león de aragon de las dos Cecilias de jerusalem de navarra de granada de toledo de balengia de galigia de mallorcas de Sevilla de gerdeña de cordova de corçega de murcia de jaén de los algarves de algezira de gibraltar de las yslas de canaria de las yndias yslas e tierra firme del mar océano conde de flandes e de tirol \& por quanto nos avernos proveydo por nuestro visorrey y capitan general de las prouinçias del peru y presidente de la abdiençia Real que en ellas reside e vos don hurtado de mendoça marques de cañete y en las provisiones que dello se os an dado no se os da poder e faccultad para encomendar los yndios que en las dichas provincias vacaren asy e como lo an hecho los nuestros governadores que an sido dellas y queriendo proveer en ello de manera que las personas que nos an seruiçio en el descubrimiento y población de la dicha tierra y en ella nos sirvieren en lo que se oviere ofrecido y ofreciere sean gratificados y Reciban merced visto por los del nuestro consejo de las yndias fue acordado que deviamos de mandar dar esta nuestra carta para vos en la dicha Razón e nos tovimoslo por bien por la qual damos licencia poder e facultad a vos el dicho don hurtado de Mendoça marques de cañete para que por el tienpo que nuestra voluntad fuere los yndios que oviere vacos quando vos llegaredes a las dichas prouinçias que no estén encomendados a personas particulares y los que vacaren durante el tienpo que vos en ellas esto vieredes los podays encomendar y encomendeys a los españoles que en ellas Resyden y Residieren según e como lo hizieron y pudieron hazer por virtud de los poderes que de nos para ello tenían el marques don françisco picarro nuestro gouernador que fue de las dichas prouincias y el liçençiado gasea nuestro presidente que fue de la abdiençia Real dellas y el nuestro visorrey don antonio de Mendoça para que los tengan e se sirvan e aprovechen dellos conforme a las hordenangas que para su buen tratamiento están hechas e las que se hizieren de aqui adelante y de la forma y manera y condiciones conque los an tenido y tienen las otras personas que tienen yndios encomendados en ellas y en las tales encomiendas preferireys a los primeros conquistadores de esas prouincjas questovieren syn 
yndios y después dellos a los pobladores casados que tovieren calidades para los tener y antes que hagays las dichas encomiendas de los yndios que vacaren proveereys que se tasen los tributos que an de dar conforme a las nuebas leyes y a las provisiones e çedulas por nos después dello dadas cerca de la dicha tasación para que aquello que fuere tasado lleben los tales encomenderos y no otra cosa alguna que para ello vos damos poder cunplido con todas sus $\mathrm{yn}^{\wedge}$ idengias y dependencias anexidades e conexidades dada en la nuestra villa de bruselas a diez dias del mes de margo de mili e quinientos e çinquenta e cinco años yo el Rey yo françisco secretario de su cesaría y católicas Magestades la fize escrevir por su mandado y en las espaldas estaban las firmas syguientes el marques el liçençiado tello de sandoval el liçençiado don Juan sarmiento el dotor vazquez Registrada ochoa de luyando por chanciller martin de Ramoyn.

\section{[al margen: encomiendo]}

Encomiendo en voz juan velazquez altamirano en la provinçia de atacama la mitad del Repartimiento de indios de la dicha provinçia que en conpañia de françisco de ysasaga tovieron encomendados pedro de ysasaga difunto y por su muerte don pedro de cordova questan vacos: por dexaçion que dellos hizo el dicho don pedro de cordova con el caçique principal que se dize donjuán coto cotar questa en atacama la grande y don françisco pachagua para que por yndiviso los tengays en encomienda en conpañia del dicho françisco de ysaga con todos sus prinçipales e yndios naturales e mitimaes pueblo y estancias a ellos subjetos e pertenecientes bien asi e según que los tovieron encomendados los dichos pedro ysaga e don pedro de cordova en virtud de las çedulas de encomienda que dellos tovieron y asymesmo vos encomiendo los yndios questan en el puerto del dicho valle de atacama que vos el dichojuan velazquez truzistes de paz e hizistes poblar que andaban deRamados con los caçiques e prinçipales dellos para que los tengays e poseays e ayays cobreys e gozeis los tributos que los naturales del dicho Repartimiento ovieren de dar conforme a la tasa que dellos se hiziere desde el dia que tomaredes la posesión de los dichos yndios en adelante en alguna gratificación de lo que aveys servido a su Magestad en el entretanto que se haze la dicha tasa vos encargo e mando que no pidays ni lleveys tributos excesyvos ni mas de aquello que buena e justamente e syn vexagion devieren e pudieren dar para ayuda a vuestra cómoda sustentación con apercibimiento que vos hago que sy en ello excedieredes se os mandara descontar la tal demasia para en parte de pago de lo que adelante ovieren de dar conforme a la tasa que se hiziere de los dichos tributos e conque no os syrvays de los yndios del dicho Repartimiento por vos ni por ynterposytas personas de ningún servicio personal en vuestra casa ni otras haziendas granxerias ni obras syn espresa licencia mia y con voluntad dellos y pagandoselo so las penas contenidas en las dichas hordenaneas e provisyones e çedulas Reales que sobre ello están dadas y con que los trate bien y procure su conservación y multiplicación y anparo e defensa y los haga dotrinar en las cosas de nuestra santa fee catolica ley natural e buena policia y sy en ello algún descuydo tovieredes cargue sobre su conciencia y no de la de su magestad e mia que en su Real nombre vos los encomiendo y por la presente mando a antonio de hoznayo coRegidor por su Magestad de la çibdad de la plata provincia de los charcas y alcaldes hordinarios dellos e a cada vno e qualquier $r$ dellos que luego que por parte del dicho Juan velazquez altamirano fuere pedida posesión de $\mathrm{s}$ los dichos yndios se la den en forma e no se la pudiendo ellos dar personalmente provean de vna persona que se la de y dada le anparen e defiendan en ella e no consyentan que della sea despojado syn primero ser oydo e vencido por fuero e por derecho so pena de cada mili pesos de oro para la camara e fisco de su magestad fecho en los Reyes a veinte dias del mes de hebrero de mili e quinientos e sesenta años el marques por mandado de su excelencia pedro de avendaño.

[al margen: hasta aquí] [rubricado]

la encomienda de los indios de los charcas en don pedro porque ha de hazer dexaçion de los de tacama.

[al margen: Encomienda de los indios charcas en don pedro de cordova. Esta es la encomienda en don pedro de cordova de confirmación de la que tenia de tacama.]

Don hurtado de mendoça marques de cañete guarda mayor de la çibdad de cuenca visorrey e capitan general en estos Reygnos e provincias del peru por su magestad \& por quanto en dias pasados en nonbre de su magestad encomendé al capitan don pedro de cordova los yndios i carangas y atacamas en que doña teresa de avendaño avia subcedido como consta e parece por la çedula de encomienda que dellos le mande dar el tenor de la qual es el que se sigue $\mathrm{H}$ don hurtado de mendoça marques de cañete guarda 
mayor de la çibdad de cuenca visorrey e capitan general en estos Rey nos e provincias del peru por su magestad $\&$ por quando vos don pedro de cordova e de avendaño pasastes a estos dichos Reygnos en mi compañia a servir a su magestad en lo que se ofreciese y por mi os fuese mandado y llegado a esta corte atento ao a la calidad e confiança de vuestra persona os e ocupado en que syrvays a su magestad con cargo de capitan de cincuenta gentiles hombres que por mi horden se an hecho juntamente con otra de çinquenta arcabuzeros para que Resydan en ella en la guarda de mi persona y por lo que conviene al servicio de su Magestad y execucion de su Real justicia y seguridad de la tieRa y atento a que soys casado con doña theresa de avendaño hija ligitima del secretario pedro de avendaño la qual tiene y pose por prouision desta Real abdiençia el repartimiento de la mitad de los yndios carangas de colquemarca de que heran caçiques e prinçipales layme e bilcamani e cayoca e cóndor e xequinaco con el principal don manuel vilcamani y ciertos yndios mitimaes e moyos moyos y el Repartimiento de yndios de la provincia de atacama que vaco por muerte de pedro de ysaga primero marido de la dicha doña theresa de avendaño y por vos el dicho don pedro de cordova me a sido pedido e suplicado que atento a lo suso dicho y a la voluntad que teneys de bibir e permanecer en esta tierra os hiziese merced de confirmar a la dicha doña theresa de avendaño vuestra muger el dicho Repartimiento y de vos dar nueva encomienda del y por mi visto e considerado lo suso dicho en nonbre de su magestad e por y virtud de sus Reales poderes que para ello tengo el thenor de los quales es el siguiente Don carlos por la divina clemencia enperador senper avgusto Rey de alemania...

[al margen: la prouision de su Magestad]

por quanto nos avernos proveydo por nuestro visorrey e capitan general de las provincias del peru y presydente de la abdiençia Real que en ella Resyde a vos don hurtado de mendoça marques de cañete y en las provisiones que dello se os an dado no se os da poder e facultad para encomendar los yndios que en las dichas provincias vacaren ansy e como lo han hecho los nuestros gouernadores que an sydo della y quiriendo proveer en ello de manera que las personas que nos han servido en el descubrimiento e población de la dicha tierra y en ella nos sirvieren en lo que se obiere ofrecido y ofreciere sean gratificados y Reçiban merced visto por los del nuestro consejo de las yndias fue acordado que deviamos de mandar dar esta nuestra carta para vos en la dicha Razón e nos tovimoslo por bien por la qual damos licencia poder e facultad a vos el dicho don hurtado de mendoça marques de cañete para que por el tienpo que nuestra voluntad fuere los yndios que oviere vacos quando vos llegaredes a las dichas provincias que no estén encomendados a personas particulares e los que vacaren durante el tienpo que vos en ellas estovieredes los podays encomendar y encomendeys a los españoles que en ellas Resyden según e como lo hizieron e pudieron hazer por virtud de los poderes que de nos para ello tenian el marques don françisco pizarro nuestro governador que fue de las dichas prouinçias y el liçençiado gasea nuestro presydente que fue de la abdiençia Real dellas y el nuestro visorrey don antonio de mendoça para que los tengan y se sirvan e aprovechen dellos conforme a las hordenancas que para su buen tratamiento están fechas y las que se hizieren de aqui adelante y de la forma e manera e condiciones con que los an tenido y tienen las otras personas que tienen yndios encomendados en ellas y en las tales encomiendas prefe-rireys a los primeros conquistadores de esas provincias questobieren syn yndios y después dellos a los pobladores casados que tovieren calidades para los tener e antes que hagays las dichas encomiendas de los yndios que vacaren proveereys que se tasen los tributos que an de dar conforme a las nuebas leyes y a las provisiones e çedulas por nos después dello dados cerca de la dicha tasación para que aquello que fuere tasado lleben los tales encomenderos y no otra cosa alguna que para ello vos damos poder cunplido con todas sus yncidencias e dependencias

[al margen: data]

anexidades e conexidades dada en la nuestra villa de bruselas a diez dias del mes de marco de mili e quinientos e cincuenta e cinco años yo el Rey yo françisco de heraso secretario de su sesaria e católicas magestades la fize escrevir por su mandado el marques el liçençiado tello de sandoval el liçençiado donjuán sarmiento el dotor vazquez el liçençiado villagomez Regis trada ochoa de luyando chanciller martin de Ramoyn confirmo apruevo e Ratifico la subcesyon del dicho Repartimiento que por muerte del dicho pedro de ysaga paso en la dicha doña theresa de avendaño vuestra muger y de nuevo en nombre de su magestad vos encomiendo el dicho Repartimiento e yndios de suso Referidos para que los tengays e poseays e gozeys por dos vidas la vuestra e vno de vuestros hijos ligitimos y en defeto de no avellos vuestra muger conforme a las provisyones Reales de su magestad que cerca de la subcesion de las tales 
encomiendas de yndios están dadas y según e de la manera que el dicho pedro de ysaga los tuvo e poseyó e le fueron encomendados por el obispo de palencia presydente que fue destos dichos Reynos en nuebe de henero de mili e quinientos e cmquenta años e gozeys de los tributos que fueren obligados a dar conforme a la tasa que dellos esta fecha o se hiziere con que no os syrvays de ningún servicio personal del dicho repartimiento por vos ni por ynter- posytas personas en vuestra casa ni otros seruiçios obras e grangerias so las penas contenidas en las hordenancas e prouysiones Reales sobre ello dadas e con que los trate bien e procure su conservación y multiplicación y les haga dotrinar en las cosas de nuestra santa fee catolica ley natural e buena policia y sy en ello algun descuydo tuviere cargue sobre su conciencia y no de la de su magestad ni mia que en su Real nombre vos los encomiendo e por la presente mando y encargo al liçençiado altamirano oydor de la Real abdiençia y cnancillería que por mandado de su Magestad reside en esta çibdad de los Reyes a cuyo cargo esta el gouierno y administración de la justicia de la provincia de los charcas e mando a su lugar teniente e alcaldes hordinarios de la çibdad de la plata y asiento de Potosi y a cada vno e qualquier dellos que luego que por parte del dicho don pedro de cordova fuere pedida posesyon del dicho Repartimiento en confinación de la que la dicha doña theresa de avendaño su muger tiene se la den e metido le anparen en ella y no consyentan que della sea despojado syn primero ser oydo e vencido por fuero e juicio lo qual hasy hagan e cunplan so pena de cada mili pesos de oro para la cámara de su magestad.

\section{[al margen: fecho año de 57]}

fecho fecho [sic] en los Reyes a veynte e cinco dias del mes de hebrero de mili e quinientos e çinquenta $e$ syete años el marques por mandado de su excelencia Juan muñoz Rico el qual parece que en virtud de la dicha çedula fue dada posesyon de los yndios del dicho Repartimiento y lo a tenido y poseydo y tiene y pose y porque la mayor parte de los yndios de la dicha encomienda están en la provincia de atacama fin de los términos de la dicha villa de la plata y entrada del despoblado para yr a la governacion de chile y en el camino Real donde conviene poblarse vn pueblo despañoles con los yndios que ay en la dicha provincia y Repartimiento de atacama la grande y la chica para que mas llanamente e syn Riesgo se pueda andar el dicho camino y pasar ganado e comunicarse esta tieRa con la dicha governacion de chile y para que tenga efeto conviene que haga dexaçion de ellos y porque quitmndole los dichos yndios no le queda con que se poder sustentar proveyendo en ello por la presente en nonbre de su magestad e por virtud de su poder Real que para ello tengo que es el que va ynserto en la çedula de encomienda que de suso va yncorporada haziendo el dicho don pedro de cordova ante todas cosas dexaçion en su magestad y en mi en su Real nonbre de los yndios atacamas del dicho Repartimiento para que su magestad cobre los tributos de ellos o haga lo que fuere seruiçio encomiendo en el dicho don pedro de cordova en los términos e jurisdicion de la dicha villa de plata el caçique guarache e prinçipales e yndios del Repartimiento de las charcas que don alonso de montemayor difunto tuvo encomendado en la dicha provincia con los demás caçiques e prinçipales e yndios naturales e mitimaes pueblos y estancias a ellos subjetos según e de la manera que el dicho don alonso de montemayor los tovo e poseyo e cobro e gozo los tributos dellos y asimesmo le encomiendo los moyosmoyos de los valles de turqui y carpachaca de que son caçiques guayniguayni y paro o sus subgesores que tovieron françisco de tapia y hernan muñoz atento que el liçençiado pedro gasea los encomendó en pedro de ysaga su antecesor en cuya encomienda subcedio como pareció por cierto proceso que se hizo se hizo [sic] ante el liçençiado altamirano oydor en el asyento de potosi por parte del dicho don pedro de cordova que ante mi se presento como cosa que le pertenece por la dicha çedula de encomienda que dellos tobo el dicho pedro de ysaga con los demas yndios para que los tenga e posea aya e cobre e goze los tributos que conforme a la tasa que dellos esta fecha o se hiziere ovieren de dar con que no se sirva dellos por sy ni por ynterposytas personas de ningún seruiçio personal en su casa ni otras haziendas grangerias ni obras syn espresa licencia mia e con voluntad de los yndios y pagándoselo so las penas contenidas en las hordenancas provisiones e çedulas Reales que sobre ello estan dadas y con que los trate bien y procure su conservacion multiplicacion anparo e defensa y los haga doctrinar en las cosas de nuestra santa fee católica ley natural e buena policía y sy en ello algun descuydo toviere cargue sobre su conciencia y no de la de su Magestad ni mia que en su Real nonbre se los encomiendo y por la presente mando al coRegidor de la dicha çibdad de la plata y alcaldes hordinarios della y a cada vno e qualquier dellos que luego que por parte del dicho don pedro de cordova fuere pedido posesyon de los dichos yndios constandole aver hecho la dicha dexaçion se la den en forma y le anparen y defiendan en ella y no consyentan que della sea despojado syn primero 
ser oydo e vencido por fuero e por derecho so pena de cada mili pesos de oro para la cámara e físco de su magestad fecho en los rreyes a seys dias del mes de novienbre de mili e quinientos e çinquenta $\mathrm{e}$ nueve años el marques por mandado de su excelencia pedro de avendaño.

La dexaçion que hizo don pedro de cordova de los yndios de atacama.

Yo antonio de quevedo escrivano de su magestad en estos sus Reynos y señorios doy fee y verdadero testimonio a los que la presente vieren como ante mi como tal escriuano en veynte dias del mes de hebrero de este presente año de mili e quinientos e sesenta años el capitan don pedro de cordova en cunplimiento de la merced e çedula de encomienda hizo dexaçion de la mitad de los yndios de atacama que tenia encomendados conforme a la çedula de encomienda aqui ynserta en su magestad y en el muy excelente señor don hurtado de mendoça marques de cañete visoRey destos Reynos por su magestad en su Real nonbre para que los provean den a quien fuere servido como parece por la dexaçion que ante mi hizo y de su pedimiento di el presente en el dicho dia siendo testigos a lo ver pedir e hazer la dicha dexaçion damian de la vandera e juan de avendaño e juan rrodriguez de herrera estantes en esta dicha çibdad de los Reyes y en fee dello lo firme de mi nonbre e fize aquí mi signo a tal en testimonio de verdad antonio de quevedo.

Replica vease porque dize que no syendo su magestad seruiçio desta contratación pide los yndios de atacama y dexara estos otros y seruira con CCCCLU maravedis.

Alonso de herrera en nonbre de don pedro de cordova vecino de la ciudad de los rreyes en el pleyto con el liçençiado vlloa vuestro fiscal rrespondiendo a la petición por el dicho fiscal presentada digo que vuestra alteza deue prouer y mandar en esta cavsa conforme a lo que por mi parte esta pedido e suplicado sin enbargo de lo en la dicha petición contenido que se escluye por lo siguiente...

Lo primero por defeto de parte y por lo demás general que aqui e por expresado lo otro porque no obsta ni prejudica al derecho de mi parte vuestra rreal çedula que dize ser dada en toledo por el mes de deziembre del año de sesenta por la qual se mando se quitase al dicho mi parte el rrepartimiento que abia sido de don alonso de montemayor porque la dicha çedula fue ganada con siniestra y menos verdadera rrelaçion que se hizo a vuestra alteza diziendo quel rrepartimiento de don alonso de montemayor el marques de cañete vuestro visorrey le avia dado en encomienda y hecho gracia y merced del al dicho don pedro de cordova mi parte como parece por la rrelaçion de la dicha çedula no siendo ni pasando ansi porque hallara vuestra alteza quel dicho virrey no hizo donación ni merced al dicho mi parte del Repartimiento que abia sido del dicho don alonso de montemayor lo que paso fue quel dicho marques de cañete por via de contratación contrato con mi parte que hiziese dexaçion de los yndios atacamas que doña teresa de avendaño su muger y el como su marido tenian en la provincia de atacama en el camino rreal ques en el pasaje para chile y tucuman y que en rreconpensa y trueco le daría los yndios charcas que son hasta ciento y sesenta y asi se hizo y efetuo el dicho trueque y avn quedo obligado el dicho virrey a cunplille los dichos yndios a numero de mili e quinientos sobre los ciento y sesenta de las charcas y otros treinta yndios moyosmoyos y por morir el dicho virrey en aquella sazon no cunplio lo que con mi parte puso de lo qual rresultan dos cosas en favor de mi parte la vna que avnque estubiera mandado por vuestra alteza que se quitara a mi parte el rrepartimiento que vbiese dado el dicho virrey a mi parte la dicha çedula y rrebocacion no se puede ni debe estender a este nuestro caso porque no fue encomienda ni merced sino contratación a la qual estaba y esta obligado el dicho virrey y la otra quel dicho mi parte quedo dañineado en la dicha contratación por no haberse cunplido con el lo que se puso en mas de mili e trezientos yndios y vuestra alteza lo deve mandar asi cunplir y el dicho vuestro visorrey tuvo poder para hazer la dicha contratación y trueco como tal virrey especialmente tiniendo el poder tan anplio como tuvo del qual hago presentación lo otro porque la dicha contratación y trueco fue muy en vuestro rreal seruiçio y en bien vniversal de la tierra por el fin con que se hizo que fue para que se hiziese población en aquella provincia de atacama para el paso de chile y tucuman por si el dicho vuestro visorrey hizo merced de los dichos yndios atacamas ajuan velasques altamirano con cargo que rresidiese en el dicho rrepartimiento con cargo de corregidor y que poblase y hiziese vecindad y tubiese bastimentos para los pasajeros que por alli pasasen lo otro porque menos obsta la çedula que se dize dada en bruselas por la qual dizen estar rrebocado el poder de encomendar yndios al dicho virrey porque niego haber tal rrebocacion ni el poder quel dicho virrey tenia se podia rrebocar por vna çedula sinple 
por ser el dicho poder dado con tantas clausulas y firmezas que para su rrevocacion se rrequerian las mismas solenidades con que se le dio lo otro porque de la dicha çedula que dizen de rrebocacion no se tubo noticia en la dicha prouinçia como se tubo del dicho poder que se publico y pregono y no constando de otra cosa todo lo que el dicho virrey hizo como virrey y bicario de vuestra alteza a de valer y tener fuerca lo otro porque avnque verdaderamente por la dicha çedula se le vbiera rrevocado el poder de encomendar yndios no se le rreboca el poder contratar como lo hizo con mi parte y asi este caso esta fuera de la dicha rrevocacion lo otro porquel dicho conde de nieva vuestro visorrey luego que entendio questa no abia sido merced de encomienda sino contratacion mando por dos avtos boluer y rrestituyr a mi parte los dichos yndios con los Rentos coRidos y asi lo debe vuestra alteza mandar y prover lo otro porque niego aber mandado vuestra alteza poner los dichos yndios en vuestra rreal cabeca porque solamente se mando poner el rrepartimiento que abia sido de lope de mendieta lo otro porque demás que mi parte tiene tan notoria justicia para lo que pretende haze ofrecimiento que no siendo vuestra alteza seruiçio que pase la dicha contratacion y trueque es contento y rrecibira merced en que vuestra alteza le mande boluer y rrestituyr sus yndios atacamas con los frutos y rrentos corridos y que corrieren hasta la rreal rrestitucion de los yndios charcas pues mi parte los a tenido y poseido con justo titulo y buena fee y demas desto servira a vuestra alteza alia con quatrocientas y çinquenta mili maravedis porque se deshaga la dicha contratacion en la manera suso dicha en lo qual conocerá vuestra alteza la poca merced que al dicho mi parte se le hizo por todo lo qual y por lo que mas juridico sea pido e suplico a vuestra alteza mande hazer y proveer en esta cavsa conforme a lo que por mi parte esta pedido y suplicado y pido sobre todo cunplimiento de justicia y costas y en lo necesario vuestro rreal oficio ynploro.

El liçençiado tobar.- Alonso de herrera.[rubricado]

En la villa de madrid a diez y siete dias del mes de henero de mili y quinientos y sesenta y quatro años en el consejo rreal de las yndias de su magestad presento esta peticion alonso de herrera en nonbre de don pedro de cordova su parte e por los señores del dicho consejo vista mandaron dar treslado a la otra parte.

[Hay una rúbrica]

notificoseme el dicho dia y año y afirmandome en lo que tengo dicho y negando lo perjudicial concluyo.

[Hay una rúbrica]

los señores del Consejo mandaron aver e Ovieron este pleyto por concluso.

[Hay una rúbrica]

[En el dorso se lee: traslado] 